\title{
Medical Education during COVID-19 Pandemic: Lessons Learnt and Future Priorities
}

\author{
Kamran Ali ${ }^{1,2}$ \\ ${ }^{1}$ Professor of Dental Education and Consultant Oral Surgery, Faculty of Health, University of Plymouth, UK \\ ${ }^{2}$ National Teaching Fellow
}

The coronavirus disease (COVID-19) caused by the novel coronavirus (SARS-CoV-2) has had the most remarkable impact on the delivery of clinical services and medical education in our living memory. Even the most advanced healthcare systems in the world have struggled to deal with the challenges of COVID-19 pandemic. It has also posed serious tests for the political leadership across the globe due to the financial and social fallout and also exposed the vulnerabilities and lack of preparedness of modern healthcare infrastructures. ${ }^{1}$ The death rate from COVID-19 in the Western world including the USA, Canada, Europe, Australia etc. and more recently in India has been alarming. ${ }^{2}$ The ongoing vaccinations against COVID-19 provide a glimmer of hope that a fair degree of normality might be restored in the future. However, the rapid emergence of mutant strains of SARS-CoV-2, and lack of clarity regarding the longevity of immune protection imparted by vaccines add to the existing uncertainties related to COVID-19. ${ }^{3}$ In addition, fake propaganda on social media platforms fueled by conspiracy theories is a barrier to widespread uptake of vaccines particularly amongst some sections of the society.

\section{Correspondence:}

Kamran Ali

Twitter: @DentalAcademic

Cite this editorial: Ali K. Medical Education during COVID-19

Pandemic: Lessons Learnt and Future Priorities. J Islamabad

Med Dental Coll. 2021; 10(2): 66-67

Doi: 10.35787/jimdc.v10i2.721
Given the risks of additional waves of COVID-19 in the future, it is unlikely that COVID-19 will be controlled fully, and the healthcare professions must continue to adapt in the light of emerging scientific evidence.

The delivery of education across the board has been through a rollercoaster ride and has faced numerous impediments since the start of the pandemic. Social distancing and cross-infection control measures have also impacted adversely on healthcare services with significant resource and logistic implications for the providers. Educational environments in healthcare settings may require appropriate physical and temporal separation measures during face-to-face teaching and training for the foreseeable future and it is sensible to have plans in place for mitigating circumstances mandated by resurgence of COVD-19 in the future. Medical educators must continue to use a blended approach for delivery of teaching and training through efficient use of technology. A range of online platforms such as, Zoom, Microsoft Teams, Google rooms, Skype, WebEx etc. along with numerous other bespoke applications have been used widely for remote teaching, assessments, meetings, interviews, and remote patient consultations etc.

During the last decade, medical institutions in the developed countries have been striving to mirror the rapid digitization of core societal functions by downsizing lectures; flipping the classroom; development of interactive digital platforms to impart active self-directed and self-paced 
independent learning activities. ${ }^{4}$ Web-based digital learning environments offer several advantages: Teachings sessions can be conducted in real time (e.g., on Zoom) with opportunities for live interactions between the facilitators and the students. Alternatively, sessions can be recorded as narrated PowerPoint presentations; podcasts, vodcasts etc. and shared with students on the digital learning environment independent of time and place, offering flexibility to the students. Findings from the developed countries show that students tend to view digital learning positively. ${ }^{5}$

A recent review of digital learning in medical education highlighted several barriers which affect the development and implementation including inadequate infrastructure, absence of institutional strategies and support, lack of technical skills and negative attitudes due to lack of familiarity. ${ }^{6}$ Development of a comprehensive business case is the first step institutions may need to take. This is essential to evaluate the feasibility and financial viability of an effective and secure digital learning platform as it requires dedicated technical support, staff and student training, availability of appropriate digital devices for staff and students, unlimited webconnectivity. It would also be sensible to conduct meaningful consultations with all stakeholders to gauge their views about online learning based on their local circumstances and experiences. Feedback from stakeholders should be used to inform the development and use of digital learning platforms for healthcare education in Pakistan.
Based on the evidence from the developed countries, a blended learning approach in medical education is here to stay for the foreseeable future. Notwithstanding the upfront financial implications, investing in digital education not only promises longterm savings of time and costs, but can also serve to enhance the quality of learning experiences for the students. Healthcare institutions in Pakistan may developing robust strategies to create comprehensive digital learning environments to facilitate education of undergraduate and postgraduate students and trainees.

\section{References}

1. Centers for Disease Control and Prevention. CDC Science Agenda for COVID-19, 2020-2023.

2. WHO Coronavirus disease (COVID-2019) situation reports. Available at: https://www.who.int/ emergencies/diseases/novel-coronavirus-

2019/situation-reports. [Accessed 12 June 2021]

3. Hodgson SH, Mansatta K, Mallett G, Harris V, Emary KRW, Pollard AJ. What defines an efficacious COVID19 vaccine? A review of the challenges assessing the clinical efficacy of vaccines against SARS-CoV-2. Lancet Infect Dis. 2021; 21(2): e26-e35. Doi: 10.1016/S1473-3099(20)30773-8

4. McGrath C, Palmgren PJ, Liljedahl M. Beyond brick and mortar: Staying connected in post-pandemic blended learning environments. Med Educ. 2021 May 12. Doi: 10.1111/medu.14546.

5. Iyer P, Aziz K, Ojcius DM. Impact of COVID-19 on dental education in the United States. Journal of dental education. 2020; 84(6): 7182. Doi: 10.1002/jdd.12163

6. O'Doherty D, Dromey M, Lougheed J, Hannigan A, Last J, McGrath D. Barriers and solutions to online learning in medical education - an integrative review. BMC Med Educ. 2018 7;18(1):130. Doi: $10.1186 / \mathrm{s} 12909-018-1240-0$ 